\title{
A eficácia das psicoterapias: apontamentos sobre uma cultura da avaliação em relatório francês de saúde
}

\section{Efficacy of psychotherapy: notes on an evaluation culture in a French health report}

\section{Eficacia de las psicoterapias: notas sobre una cultura de evaluación en un informe francés de salud}

\author{
Letícia Vier Machado* \\ Universidade de São Paulo - USP, São Paulo, São Paulo, Brasil
}

\section{Fernando Aguiar**}

Universidade Federal de Santa Catarina - UFSC, Florianópolis, Santa Catarina, Brasil

\begin{abstract}
RESUMO
A crescente expansão das ciências cognitivas na última década tem confrontado a psicanálise como método terapêutico e questionado a respeito de sua eficácia terapêutica. Em 2004, a Direção Geral da Saúde francesa solicitou a um grupo de peritos que realizasse um relatório de avaliação das principais psicoterapias presentes na França e examinasse a eficácia dos tratamentos empreendidos. O objetivo do artigo, resultante de pesquisa teórico-bibliográfica, é apresentar parte desta história recente da psicanálise na França, com a descrição do relatório publicado, analisado e discutido à luz de textos psicanalíticos ou sobre psicanálise. Procuramos explorar seus impasses e algumas questões políticas e econômicas que atravessam a publicação, que concluiu pela ineficácia da psicanálise em relação às demais abordagens avaliadas. As conclusões ressaltam a importância atribuída pela cultura às práticas avaliativas e à busca do completo estado de bem-estar, para em seguida apontar alguns vieses da avaliação da psicanálise pelo método da medicina baseada em evidências e esclarecer as repercussões do relatório na França uma década depois sobre o tratamento do autismo por psicanalistas.
\end{abstract}

Palavras-chave: psicanálise, psicoterapia, avaliação, eficácia.

\begin{abstract}
The growing expansion of cognitive sciences in the last decade has confronted psychoanalysis as a therapeutic method and questioned its therapeutic efficacy. In 2004, the French General Directory of Health demanded a group of experts to conduct an evaluation report on the major psychotherapies practiced in France, and to examine the effectiveness of the treatments undertaken. This article results from a theoretical and bibliographical research and aims to present part of the recent history of psychoanalysis in France, describing the published report, analysing, and
\end{abstract}


discussing it, with the support of psychoanalytic texts or texts about psychoanalysis. We explore the report's impasses as well as some political and economic issues that permeated the publication, which concluded the ineffectiveness of psychoanalysis compared to other approaches evaluated. The findings show the cultural importance given to evaluation practices and to the pursuit of a complete state of well-being. In sequence, they point out some biases in the psychoanalytic evaluation conducted under the evidencebased medicine method and clarify the report's repercussions on the treatment of autism by psychoanalysts in France a decade after.

Keywords: psychoanalysis, psychotherapy, evaluation, efficacy.

\section{RESUMEN}

La creciente expansión de la ciencia cognitiva en la última década se ha enfrentado el psicoanálisis como método terapéutico y cuestionado su eficacia terapéutica. En 2004, el Director General de la Salud de Francia pidió a un grupo de expertos para llevar a cabo un informe de evaluación de las principales psicoterapias presentes en Francia, y examinar la eficacia de los tratamientos realizados. El propósito del artículo, que resulta de investigación teórica y bibliográfica, es dar a conocer parte de esta historia reciente del psicoanálisis en Francia, describiendo el informe publicado, analizado y discutido a la luz de los textos psicoanalíticos o acerca del psicoanálisis. Exploramos sus impasses y algunas cuestiones políticas y económicas que atraviesan la publicación, la cual señala la falta de efectividad del psicoanálisis en relación con otros enfoques evaluados. Las conclusiones ponen de relieve la importancia otorgada por la cultura a las prácticas de evaluación y a la búsqueda del estado completo de bienestar, a continuación, señalan algunos sesgos de la evaluación del psicoanálisis por el método de la medicina basada en evidencias y aclaran las repercusiones del informe en Francia una década después en el tratamiento del autismo por los psicoanalistas.

Palabras-clave: psicoanálisis, psicoterapia, evaluación, eficacia.

\section{Introdução}

Críticas em diferentes expressões acompanharam a psicanálise desde sua criação: críticas pessoais a Freud, críticas epistemológicas em relação à cientificidade da psicanálise, críticas leigas em relação à teoria da sexualidade, críticas ao dogmatismo das instituições psicanalíticas, entre muitas outras. Na última década, a hegemonia e a crescente expansão das ciências cognitivas têm confrontado a psicanálise como método de tratamento, sobretudo no que tange a sua eficácia terapêutica.

$\mathrm{Na}$ França, território no qual a psicanálise firmou-se como um elemento da cultura, penetrando em diversas esferas do Conhecimento (Literatura, Psicologia, Filosofia, Psiquiatria), o conflito entre terapias cognitivo-comportamentais e psicanálise, bem como os sucessivos ataques e acusações de impostura à disciplina freudiana adquiriram especial importância na última década. Em 2004, a Direção Geral da Saúde francesa solicitou a um grupo de peritos que realizasse um relatório de avaliação das principais psicoterapias 
presentes na França e, pautados na produção internacional sobre o assunto, examinasse a eficácia dos tratamentos empreendidos.

Este artigo tem como objetivo apresentar parte desta história recente da psicanálise na França, principiando com a descrição do relatório de avaliação das três abordagens em psicoterapia (psicodinâmica, familiar e cognitivo-comportamental), publicado pelo Institut National de la Santé pour la Recherche Médicale (INSERM) na França, no ano de 2004. O estudo resultou de uma pesquisa teórico-bibliográfica, realizada a partir daquele ano e naquele país. Recorrendo, para sua análise e discussão, a textos psicanalíticos ou sobre psicanálise, procuramos explorar os impasses deste relatório, bem como alguns atravessamentos da publicação, desvelando interesses políticoeconômicos na indicação de tratamentos psicoterápicos pelos sistemas públicos. O documento, como era de se esperar e como veremos, concluiu pela ineficácia da psicanálise em relação às demais abordagens avaliadas.

Em seguida, submetemos o relatório a uma análise crítica, situando-o num contexto mais amplo, denominado pela psicanalista Agnès Aflalo (2012) de uma "cultura da avaliação", constituída historicamente pela crescente importância atribuída pela cultura às práticas avaliativas e à otimização dos comportamentos como expressivos de um almejado e completo estado de bem-estar. Por último, exploramos alguns vieses da avaliação da psicanálise pelo método da medicina baseada em evidências e as repercussões do relatório na França, refletidas ainda hoje, mais de uma década depois, na polêmica sobre o tratamento do autismo por psicanalistas.

\section{Psicoterapia: Três Abordagens Avaliadas}

Na exaustividade de suas 553 páginas, o aparecimento do relatório de avaliação das psicoterapias na França foi uma resposta aos questionamentos da Direção Geral da Saúde (DGS), em conjunto com associações de pacientes UNAFAM e FNAP-PSY, que solicitavam ao Ministério da Saúde a facilitação do acesso às psicoterapias. Três abordagens em psicoterapia foram avaliadas a partir do que se produziu a respeito na literatura internacional: a psicoterapia dinâmica (considerada no estudo como sinônimo de psicanálise), a psicoterapia cognitivo-comportamental e a psicoterapia familiar e de casal. Os peritos elencados deveriam reunir os conhecimentos científicos sobre o assunto, analisar as publicações e produzir uma síntese dos resultados.

No documento, ressalta-se que na França as psicoterapias não são consideradas atos técnicos, de acordo com a regulamentação dos cuidados. Prescritas por médicos psiquiatras, psicólogos e médicos generalistas ou outros profissionais da saúde, as psicoterapias são 
definidas como tratamentos de utilização largamente difundida na prática de cuidados para os transtornos mentais no adulto, adolescente e criança (Expertise Collective, 2004). Mais adiante, a definição é ampliada: "[psicoterapias são] métodos psicológicos cujo objetivo é aliviar um sofrimento dentro de um quadro contratual" (Expertise Collective, 2004, p. 35).

O relatório deve ser lido como uma manobra política, já que se insere no contexto de votação da lei de Saúde Pública na França, além de resultar de uma sequência de propostas de leis e relatórios anteriores. O diretor da DGS, William Dab, era declaradamente partidário das terapias cognitivo-comportamentais (Aflalo, 2012). Entre os colaboradores do estudo, estão psicólogos e psiquiatras, bioestatísticos e epidemiologistas. J.-M. Thurin, psiquiatra e psicanalista, redigiu o capítulo referente às técnicas psicodinâmicas e se distanciou do grupo de trabalho desde a publicação dos resultados (Fischman, 2005). Outros atuaram como consultores do estudo, dos quais se destaca a participação de Daniel Widlöcher, quem em 2001 era presidente da International Psychoanalysis Association (IPA) e no relatório atuou como consultor do lado da psicanálise para a elaboração do relatório do INSERM. Seus trabalhos mais recentes ensaiam uma aproximação entre terapias cognitivo-comportamentais (TCCs) e psicanálise, uma espécie de "psicanálise cognitiva" (Aflalo, 2012). A versão psicanalítica de Widlöcher, adotada no texto do INSERM, é de um inconsciente como pensamento, como função cognitiva. O ex-presidente da IPA ainda considera que a psicanálise estaria ameaçada pelas psicoterapias, "mais rápidas e mais baratas" (Aflalo, 2012, p. 33).

É ainda relevante acrescentar que a psicanálise freudiana, na visão cognitiva, é definida como biológica e dinâmica, fazendo referência ao cérebro e aos neurônios como passíveis de reorganização ao longo do processo psicoterápico. Nesse sentido, a psicanálise consistiria em

uma ajuda psicológica externa e a organização de um quadro particular no qual o pensamento poderá se desdobrar e seus principais traços poderão ser descritos 'graças ao emprego de um pequeno número de fórmulas psicológicas' (Expertise Collective, 2004, p. 50).

O psicanalista, descrito sob as lentes do cognitivismo, aparece como aquele que interpreta e completa, em uma perspectiva interacional, permitindo a tomada de consciência de elementos "pré-psíquicos" (Expertise Collective, 2004, p. 50). O inconsciente é anulado e se torna pensamento, aproximando a grade de leitura avaliativa da psicanálise às ciências cognitivas. Do mesmo modo, a fala e a linguagem - instrumento de trabalho (Freud) e estrutura do inconsciente (Lacan) - são traduzidas para o cognitivismo como 
"verbalização" capaz de aliviar um sofrimento pela "tomada de consciência" (Expertise Collective, 2004, p. 52).

Essas ideias são especialmente difundidas na versão norte-americana da IPA, da qual Widlöcher é o representante na França. Após a morte de Lacan, nos anos 1980, a IPA iniciou um processo de cognitivização da psicanálise, em nome da "ciência". Cindida em várias correntes, decidiu reassegurar sua unidade pela ortodoxia, estabelecendo uma prática homogênea para todos (Aflalo, 2012). O próprio deslizamento de significantes no relatório, entre psicoterapia psicodinâmica, psicanálise e psicoterapia psicanalítica é sintoma de sua inconsistência. Assim, no relatório da INSERM a palavra psicanálise não se apaga, mas é muitas vezes substituída por psicodinâmica, por ser esse um "termo menos comprometedor" (Aflalo, 2012, p. 124).

No intuito de justificar a inaplicabilidade da psicanálise stricto sensu no sistema de saúde pautado na relação custo-benefício (eficácia), os autores do relatório afirmam que "seguindo as normas formais francesas, uma psicanálise necessita de um número de sessões ao menos igual a três por semana, com duração de aproximadamente 45 minutos, o paciente estando deitado. Um tratamento psicanalítico se estende por vários anos" (Widlöcher \& Abel Prot, 1996, apud Expertise Collective, 2004, p. 56).

O relatório é subdividido em seções: a primeira, Dados gerais sobre a avaliação da eficácia, trata de aspectos teóricos, metodológicos e epistemológicos sobre a avaliação da eficácia. Foi elaborado um estado da arte da avaliação da eficácia das psicoterapias, com base no conjunto de artigos recolhidos de bases de dados internacionais, totalizando mais de 1.000 (Expertise Collective, 2004).

Os aspectos metodológicos do estudo englobam esclarecimentos sobre o procedimento e a análise dos dados, explicitando a forte preocupação com o rigor do método científico. Argumenta-se que o procedimento tradicional da ciência de testar hipóteses refutáveis por meio de experiências reprodutíveis estatisticamente é aplicável ao caso das psicoterapias, com a peculiaridade de cruzar uma medida subjetiva (de um estado de ânimo, por exemplo) com a objetividade da experiência (Expertise Collective, 2004). Os aspectos epistemológicos versam principalmente sobre o histórico da avaliação da eficácia em psicoterapias.

Assim, a questão se podemos avaliar cientificamente a eficácia de uma psicoterapia é respondida afirmativamente, com o argumento de que os problemas da avaliação da eficácia em psicoterapia são os mesmos apresentados pela ciência de modo geral (Expertise Collective, 2004). O método utilizado no estudo constituiu-se de meta-análises de estudos anteriores, separando o tratamento de quadros diagnósticos extraídos dos critérios do Manual Diagnóstico e Estatístico de Transtornos Mentais (DSM) e da Classificação 
Internacional de Doenças (CID-10); e os efeitos (a eficácia) da psicoterapia sobre o quadro apresentado.

A maioria das meta-análises de estudos controlados têm considerado como critério de eficácia a redução dos sintomas mais representativos do transtorno estudado. O relatório se propôs a ir além desses critérios, considerando a effectiveness, entendida como utilidade clínica: considera-se o bloco da redução dos sintomas somada à melhora da capacidade na manutenção dos papéis social e profissional, além da qualidade de vida do paciente e da família. Enquanto a efficacy reflete o resultado dos estudos controlados com validade interna do protocolo, a effectiveness contempla os resultados das psicoterapias conduzidas em condições reais, sem seleção prévia de pacientes (Despland, 2006).

O procedimento adotado nas meta-análises do estudo foi o uso de protocolos randomisados pautados no testemunho do paciente nas fases de intervenção $(A)$ e não-intervenção $(B)$ : depois de mensurar vários comportamentos de base $(A)$, introduzia-se para cada um dos comportamentos a intervenção terapêutica (B). Espera-se que ocorram mudanças comportamentais após a intervenção, indicando um efeito específico do tratamento sobre elas (Expertise Collective, 2004).

A expertise descreve que procurou controlar nos estudos analisados a variável do efeito placebo (a sugestão), estabelecendo que a crença do paciente e do terapeuta na terapia seria critério fundamental. Não poderia ser diferente, já que o terapeuta sabe sobre a terapia que administra, e o paciente não tardaria a descobrir o mesmo. Então, o grupo placebo recebia uma terapia "sem efeitos", sem técnicas, mas semelhante a uma verdadeira terapia (Expertise Collective, 2004, p. 18).

Enfim, radicalizando a proposta de mensurar a eficácia terapêutica das psicoterapias, os peritos utilizaram o conceito de "tamanho do efeito terapêutico" para complementar as clássicas análises estatísticas, cunhado por Mary Lee Smith e Gene V. Glass na década de 1970. O tamanho do efeito é uma medida estatística definida nos seguintes termos: "para um dado critério que estudamos ao final do tratamento, consiste na diferença de distribuição entre o grupo estudado e sua comparação (grupo controle ou outro tratamento)" (Expertise Collective, 2004, p. 23). Assim, entre 0.20-0.50 considerase 0 efeito pequeno; entre 0.50 e 0.80 , médio; acima de 0.80, grande.

\section{Conclusões do Relatório: a Ineficácia da Psicanálise}

Apesar de reconhecer que a avaliação de outras terapias, como a familiar e a psicanalítica, são mais "difíceis" de realizar em 
comparação às TCCs, o estudo prossegue com a apresentação de suas conclusões. A hierarquia do balanço das avaliações estabeleceu que as TCCs eram consideradas "geralmente superiores" e com efeitos mais estáveis em relação a outras abordagens, pelo cálculo do tamanho do efeito (Expertise Collective, 2004).

Em mais de um estudo considerado, as psicoterapias psicodinâmicas são comparadas em sua eficácia à terapia de apoio (placebo). Por outro lado, os resultados de provas de eficácia das TCCs são considerados abundantes. Para as terapias familiares e de casal, quando consideradas eficazes, não raro utilizam técnicas cognitivocomportamentais. Assim, na hierarquia da expertise, só há dois lugares possíveis para a psicanálise, confundida na rubrica "psicoterapia psicodinâmica": sua eficácia é menor ou igual às TCCs, enunciando a tomada de posição pró-TCC, de modo que, ao final do relatório, já não se fala mais em psicoterapias, mas em TCC e nãoTCC.

O que determina, para o INSERM, a eficácia de uma psicoterapia? Ancorados no paradigma da cura médica, a eficácia é centrada na remissão do sintoma, de acordo com os critérios definidos pelos manuais diagnósticos. Ao apontar a limitação de se centrar na "objetividade" do sintoma, os peritos ampliam o escopo da eficácia: para a psicanálise ser considerada eficaz, além da cura do sintoma, deveria apresentar resultados de aumento na produtividade, melhoria do prazer nas relações sexuais, melhoria nas relações sociais e aquisição de consciência para lidar com conflitos psicológicos (Expertise Collective, 2004). Não seriam essas, enfim, as características que resumem o sujeito contemporâneo, sem furos, ficcionalmente mediano e regido pelo imperativo do gozo?

Caberia ilustrar esse argumento com o exemplo retirado do próprio documento. Um dos estudos considerados pela expertise avaliou os efeitos da interpretação psicanalítica. Depois de feita a interpretação, - critério da avaliação era a resposta afetiva do paciente: se defensiva, indicava um resultado negativo da interpretação; se positiva, a interpretação teria sido bem-sucedida. A conclusão do estudo é de que o efeito da interpretação sobre o afeto do paciente "sugere que um terapeuta deveria modificar sua abordagem quando - paciente mostra uma tendência a respostas defensivas a suas intervenções" (Expertise Collective, 2004, p. 88). Dito de outro modo, é proibido causar mal-estar quando impera a compreensão de saúde como o estado de completo bem-estar.

No total, onze meta-análises sobre diversos transtornos (esquizofrênicos, neuróticos, do humor, etc., de acordo com o DSM IV) foram analisadas para concluir sobre a ineficácia da psicanálise. Uma extensa apresentação dos estudos consultados é realizada em 70 páginas do documento, descrevendo cada um dos estudos em termos de objetivos, técnicas utilizadas, população e resultados 
obtidos. Destas, apenas uma se refere a pacientes neuróticos, sendo que o estudo data da década de 1980, feito nos Estados Unidos (Expertise Collective, 2004).

Nesses moldes, as conclusões gerais da expertise não surpreendem:

Uma prova de eficácia pode ser afirmada para os transtornos da personalidade, em particular para o transtorno de personalidade borderline. Existe uma presunção de eficácia, sustentada por estudos controlados randomisados, para o transtorno de pânico (com antidepressivos) e para o estado de estresse pós-traumático. Concernente à depressão, os estudos associam geralmente os resultados específicos para esse transtorno àqueles de outros transtornos (notadamente ansiosos e da personalidade), refletindo a complexidade das populações tratadas. Um estudo controlado concernente à depressão maior mostra que a associação de uma psicoterapia psicodinâmica a um tratamento antidepressivo em pacientes tratados em ambulatório tem um efeito benéfico significativo com melhoria do funcionamento global e diminuição da taxa de hospitalização em função do tratamento. As terapias psicodinâmicas (psicanalíticas) breves originaram mais estudos de avaliação que as psicoterapias analíticas de longa duração. São, sobretudo, essas últimas que devem ser objeto de estudos futuros (Expertise Collective, 2004, p. 158).

Eficácia comprovada para os transtornos da personalidade e somente presunção de eficácia para outros diagnósticos. Cabe ressaltar que a presunção de eficácia é indicada quando encontradas uma ou várias meta-análises ou estudos controlados que se contradizem ou necessitam de confirmação, enquanto a prova de eficácia deriva da convergência dos estudos e de forte potência estatística. Por outro lado, se é constatado o sucesso no tratamento da depressão, por exemplo, é porque a psicanálise foi associada a um tratamento medicamentoso. A conclusão geral é que devem ser produzidos mais estudos científicos sobre a psicanálise, entendida como psicoterapia analítica de longa duração.

O documento expõe ainda as seções teóricas dedicadas às TCCs e à terapia familiar e de casal. Enquanto o texto sobre psicanálise é repleto de referenciais, em uma bricolagem de conceitos explicados de forma simplista, o texto sobre as TCCs é escrito livremente, não referenciado, demarcando o posicionamento dos peritos. Definidas como "a aplicação de princípio oriundos da psicologia científica na prática clínica" (Expertise Collective, 2004, p. 169), as TCCs tiveram como precursor na França Pierre Janet. Os peritos afirmam a presença central dessas terapias hoje, na França, devido aos estudos 
controlados e meta-análises, financiados, não por acaso, pelo INSERM, organizador deste relatório.

Contudo, queixam-se do atraso da França em relação aos países da Europa em matéria de terapias, já que as TCCs não dispunham de reembolso. Diferentemente dos estudos com a abordagem psicanalítica, aqui os peritos excluíram estudos "muito antigos", com vieses ou cujos objetivos não respondiam aos critérios da análise. Quanto às conclusões, as TCCs são consideradas eficazes para a maior parte dos transtornos avaliados, de acordo com os critérios do DSM ou CID-10; são ainda consideradas, pelos peritos, mais eficazes que outras abordagens e com ganhos que se sustentam no tempo. Se combinadas a medicamentos psicotrópicos, a eficácia é ainda maior, e o tempo exigido é mais curto, respondendo ainda melhor à demanda econômica da melhor relação custo-benefício (Expertise Collective, 2004).

Entretanto, no mesmo período da elaboração do relatório na França, os alemães Leichsering e Leibing realizaram em 2003 um estudo comparando a eficácia das TCCs e das "terapias analíticas" para os transtornos da personalidade, concluindo pela superioridade do tamanho do efeito das terapias psicanalíticas (Expertise Collective, 2004). Os peritos se prontificaram a afirmar e apontar falhas metodológicas do estudo, como o uso de um método antigo e a indeterminação do número de sujeitos, entre outros.

Outro estudo alemão, de Leichsenring e Rabung (2008, apud Dunker, 2011) chegou a considerações semelhantes, contrárias às conclusões do INSERM. Intitulado "Psicanálise e Psicoterapia Psicodinâmica de Longo Prazo", os pesquisadores reuniram mais de mil estudos clínicos sobre análise da eficácia de tratamentos realizados em tempo superior a um ano ou 50 sessões, produzidos entre 1960 e 2008. As conclusões são resumidas por Dunker (2011): ao comparar as psicoterapias de longo prazo com outras formas de psicoterapia, inclusive as TCCs, constatou-se que a 'psicoterapia psicanalítica' é duas vezes mais eficaz em termos de 'efetividade genérica'; mais eficaz em problemas focais; problemas funcionais de personalidade; problemas relativos ao funcionamento social e para os sintomas específicos. Frente a quadros complexos, como transtornos de personalidade, o tratamento psicanalítico mostrou taxa de melhora de $96 \%$ superior a outras abordagens. Em contrapartida, os efeitos do tratamento psicanalítico eram reduzidos quando acompanhado de medicação psicotrópica. Com o estudo, os autores ainda rebateram a tese de que à cura de alguns quadros correspondem certas técnicas. Em suma, "os autores estimam que mais de 300 estudos, com resultados opostos, seriam necessários para inverter os resultados desta meta-análise de significativos para não-significativos" (Dunker, 2011, p. 579). Se resta algo que limite a eficácia da psicanálise, e usamos o termo com cautela, é seu alto custo. 
Quanto às terapias familiares, especial ênfase é atribuída àquelas de abordagem cognitivo-comportamental, classificadas entre as "novas concepções", em detrimento das demais abordagens (sistêmicas, psicanálise familiar, terapia familiar psicodinâmica, terapias transgeracionais); ressaltando novamente sua confiabilidade científica (Expertise Collective, 2004).

Passando às conclusões, os resultados dos estudos controlados e meta-análises comparados são divididos entre eficácia por abordagem e por transtorno avaliado, segundo as categorias do DSM. De qualquer modo, na lógica tecnicista, a psicanálise está sempre em desvantagem. Quanto às terapias de família e casal, o resultado exposto por abordagem se resume em: eficácia e especificidade da terapia de base comportamental; eficácia possível para a terapia do insight - outro deslizamento de termo para a psicanálise (Expertise Collective, 2004). Em outras palavras, se a chamada terapia pelo insight dá indícios de eficácia, é preciso reconhecer as lacunas metodológicas nessa avaliação. Não tardará, mais adiante no documento, a ser considerada como a única declaradamente ineficaz, ou ainda, capaz de produzir resultados negativos (Expertise Collective, 2004).

Por fim, os estudos são sintetizados em uma tabela que define o "nível de prova" da eficácia. Para a psicanálise, a tabela apresenta prova de eficácia apenas em uma meta-análise sobre os transtornos da personalidade. Por outro lado, os resultados de provas de eficácia das TCCs são inúmeros (Expertise Collective, 2004, p. 501): prova de eficácia em agorafobia, estados depressivos, esquizofrenia, personalidade borderline, bulimia etc. Para as terapias familiares e de casal, a prova de eficácia é constatada para esquizofrenia, alcoolismo, autismo infantil, hiperatividade e transtornos de conduta em crianças (Expertise Collective, 2004, p. 516).

Aos resultados quase inquestionáveis deste documento, resta apenas situá-lo no curso da história para compreender que ele não está descolado de uma cultura avaliativa, solidamente constituída e cada vez mais presente em todos os domínios da vida, pautada nos ideais de mensuração e quantificação, da qual se revela como produto.

\section{Cultura da avaliação}

Em O mal-estar na civilização, publicado em 1930, ao discutir o enigma humano da busca pela felicidade, Freud (2010a) anuncia três fontes do sofrimento humano que barram esse objetivo comum: 0 sofrimento do próprio corpo, do mundo externo e da natureza e das relações sociais. Ultrapassar essas barreiras e seguir em direção ao gozo absoluto é tentador enquanto meta para atingir a felicidade, distanciando-se das fontes do sofrimento. 
Contudo, prossegue Freud (2010a), em relação ao sofrimento oriundo do social, custa-nos compreender por que as instituições não trazem bem-estar, se criadas por nós mesmos. Ao contrário, é a própria civilização que traz o mal-estar: "parece fora de dúvida que não nos sentimos bem em nossa atual civilização [...]" (Freud, 2010a, p. 47). Esse mal-estar não é singular, mas antes um conjunto de manifestações indiferenciadas (Miller \& Milner, 2006). O mal-estar na civilização anunciado por Freud no início do século XX permanece atual e intensificado, assumindo hoje a face da avaliação.

A avaliação é um dos males difusos, fonte de sofrimento e desprazer que traz em seu bojo a promessa da felicidade nunca garantida. A figura do pai que limita o gozo, fundamento da vida comum, aparece revestida na face da ciência, que perpetua a ilusão da completude de um saber infinito e sem furos. Como não aludir à religião que, ao procurar suprir o desamparo infantil e a nostalgia do pai, sutura nos homens a falta pela ilusão da completude e da felicidade?

O saber produzido pela ciência, causa de muitos mal-estares que visava remediar, fragmenta-se hoje em mercadorias e bens outrora inalienáveis, comercializando o corpo e a "mente" (Aflalo, 2012). Os discursos cientificistas se multiplicaram, com o objetivo de eliminar sintomas e promover a cura mais eficaz e mais rentável para 0 Estado, por meio da disseminação de práticas avaliativas no campo das psicoterapias e da saúde de modo global: a saúde mental tornouse um fator eminentemente político.

A essa aliança saúde-política, Michel Foucault (1988) denominou biopoder para designar uma economia e uma racionalidade moderna de poder, exercida positivamente sobre a vida e sobre as populações - um poder antes biológico do que jurídico. A era do biopoder foi inaugurada com a proliferação das técnicas e disciplinas variadas para garantir a gestão dos corpos e das populações, alocadas "[...] no terreno das práticas políticas e observações econômicas, [...]; explosão, portanto, de técnicas diversas e numerosas para obterem a sujeição dos corpos e o controle das populações" (Foucault, 1988, p. 131-132).

Gerir a vida, garanti-la, calculá-la e multiplicá-la: eis o princípio do biopoder. Desenvolvido ao longo do século XVII pela abordagem do corpo como máquina, ele visava ampliar as aptidões do corpo, sua utilidade e docilidade a fim de integrá-lo em sistemas de controle. Contudo, a partir da metade do século XVIII, seu exercício incide principalmente sobre o corpo-espécie, sobre a "mecânica do ser vivo" e sobre os processos biológicos de mortalidade, natalidade, nível de saúde, duração da vida; intervindo sobre eles para os regular (Foucault, 1988).

A impostura do relatório do INSERM, mais do que a metodologia utilizada ou as cifras produzidas, está na própria iniciativa de avaliar, disseminada em todos os setores das democracias modernas (Aflalo, 
2012). Quantificar o subjetivo, medir o sofrimento psíquico - e, por conseguinte, os custos para a saúde - e esquadrinhar o sujeito na soma de suas partes caracteriza essa histórica "cultura da avaliação".

\section{Panorama histórico sobre as práticas avaliativas: o ideal de saúde mental}

O primeiro estudo controlado e randomizado registrado no campo das práticas do psiquismo ocorreu no domínio da psiquiatria, com a avaliação da validade da teoria do magnetismo animal de Franz Anton Mesmer, conhecida como "mesmerismo". Os avaliadores compuseram uma comissão de peritos da Academia de Ciências e da Sociedade Real de Medicina "nomeada por Louis XVI em 1784, [e] composta por Lavoisier, Benjamin Franklin e Guillotin" (Despland, 2006, p. 1039).

A teoria de Mesmer originada no século XVIII como método de cura é acordada como a origem das psicoterapias modernas. Para ele, as doenças nervosas se originavam do desequilíbrio no "fluído universal" circulante no organismo e tratamentos psicológicos poderiam ser feitos por meio do bloqueio de fluidos corporais: bastava que 0 indivíduo bebesse água imantada, pois assim o magnetismo se transmitiria ao corpo. Além disso, acreditava que o fator de cura provinha do próprio médico, o que originaria as teorias da sugestão e o fator da transferência em psicanálise (Roudinesco \& Plon, 1998).

Mesmer tornou-se objeto de interesse para a ciência devido ao sucesso de seus tratamentos magnéticos. A comissão nomeada pelo rei realizou um estudo que comparou os efeitos da água magnetizada com o não uso em pacientes que não sabiam sobre a distinção de ambas. Porém, quando as duas estratégias, emprego ou não da água magnetizada, se demonstraram eficazes, concluiu-se que o efeito terapêutico resultava do poder da sugestão humana e não da água magnetizada em si. Desde então, com a ascensão da medicina científica, as práticas terapêuticas são por ela sobrepostas: Mesmer foi qualificado de charlatão e sua teoria, invalidada, caiu no esquecimento.

Foi nesse momento histórico, quando a medicina e a relação do médico para com ela sofrem uma transformação radical que a problemática da cura passa a integrar a agenda social. Foucault (1988), já referido, trata a questão a partir da noção de biopolítica quando, em meados do século XVIII, o corpo se torna centro de governo, proliferam as políticas de regulação da vida e a estatística torna-se a ciência por excelência do Estado.

Ao longo do século XVIII, a medicina clínica havia se ocupado da nosologia do sintoma, com fins de aprendizagem. Contudo, é no século XIX que se firma a medicina moderna, tendo como um de seus marcos o ideal de saúde e de cura para ocupar o lugar do discurso 
religioso da salvação, predominante até então (Martins, 2012). Por conseguinte, fortifica-se a política econômica do poder sobre a vida, a fim de produzir uma sociedade normalizadora e reguladora, guiada pelo ideal da saúde.

O campo de vigilância do Estado é ampliado, uma vez que a saúde (e a saúde mental) torna-se direito de todos, enquanto a doença (mental) se restringia a alguns poucos internados. Sobre a lei, predomina a norma e os finos aparelhos reguladores e corretivos: "Nessa conjuntura [proliferação de tecnologias, investimentos no 'fazer viver', condições de vida, de saúde etc.] torna-se necessário avaliar, qualificar, medir, hierarquizar as condições de vida $[\ldots]^{\prime \prime}$ (Martins, 2012, p. 61). As políticas de saúde mental nos Estados democráticos, aliadas à psiquiatria moderna e aos instrumentos diagnósticos cada vez mais apurados garantem a tênue separação entre os normais e os anormais; e se desenvolve o campo da epidemiologia como forma de prevenção na saúde mental (Aflalo, 2012; Roudinesco, 2005).

O Estado, então, amplia o exercício de seu poder sobre os sujeitos: o mal-estar é controlado, medido e avaliado à medida que se propaga a ideia de que a saúde mental é incumbência do Estado. Hoje, em pleno século XXI, o discurso médico que veio se consolidando desde 0 século XIX incorpora cada vez mais a ideia da saúde como mercadoria, firmando sua aliança com o discurso neoliberal. Como explicita Grosbois (2007), o próprio vocabulário expressa essa mudança, uma vez que substitui o paciente pelo cliente, e o tratamento pela aprendizagem:

Expressões como tratamento cedem pouco a pouco o lugar àquelas de aprendizagem, desenvolvimento de novas competências, responsabilização, até mesmo florescimento de tal ou qual aspecto de si. O paciente se metamorfoseia em cliente, usuário, beneficiário, até mesmo pessoa em dificuldade e a noção mesma de saúde se refere menos hoje à ausência de doença que ao desenvolvimento de certo potencial de adaptação acessível por um trabalho do chamado usuário sobre ele mesmo e, no caso de falhas, sobre sua rede de pertencimento [...] (Grosbois, 2007, p. 400).

Com efeito, a modificação da noção de saúde ocorreu precisamente em 1978, por iniciativa da Organização Mundial da Saúde, que passou a defini-la como o estado de bem-estar físico, mental e social (Aflalo, 2012). Curiosamente, a França não adota essa definição, deparando-se com a dificuldade de definir oficialmente o conceito de saúde mental, ainda que existam documentos oficiais que descrevam os objetivos e as orientações das políticas de saúde mental. 
Sem retornar exaustivamente à história, cabe recuperar como as práticas avaliativas corroboraram, ainda que indiretamente, para a construção da definição de saúde como bem-estar. Nascidas nos Estados Unidos no período da Segunda Guerra Mundial, as práticas avaliativas são fruto do interesse pelo controle da produção. $O$ discurso da ciência adentrou o campo industrial nos anos 1930, quando o estatístico Walter Shewhart (1891-1967) e cientistas americanos inauguraram a "qualidade" como método de controle estatístico da fabricação industrial, visando otimizar a produção (Aflalo, 2012). O método da qualidade total adquiriu visibilidade nas pesquisas do psicólogo Elton Mayo (1880-1949) que pretendia a melhoria do controle da produtividade dos operários. Doravante, as qualidades do trabalhador tornaram-se objeto de estudo e avaliação e os trabalhadores que não atingiam o desempenho almejado eram substituídos por outros mais ágeis e produtivos.

O método de controle da qualidade total foi exportado para o mundo e aprimorado no Japão, haja vista a fama da indústria japonesa do pós-guerra; e a avaliação se firmou como um saber confiável e científico. O controle da qualidade (humana) sai em busca das falhas, no intuito de produzir mais, com o menor custo e no menor tempo possível. Constatado o "sucesso" dos instrumentos e procedimentos de mensuração e quantificação, a prática de avaliação não tardou a ser transposta para outros domínios, dentre eles, 0 das psicoterapias... e da psicanálise.

\section{A Psicanálise avaliada pela Ciência}

Roudinesco (2000) situa o marco das avaliações da eficácia dos tratamentos psicoterápicos e psicanalíticos em 1952, fruto de pesquisas estadunidenses. Desde o pós-guerra, as classificações e a estatística estavam em declínio, em decorrência da derrota das ideologias fascistas que delas faziam uso, e psiquiatras do mundo inteiro engajaram-se na sua revitalização (Aflalo, 2012).

As dificuldades em levar a cabo tais estudos, assim como os resultados encontrados, em muito se assemelham àquelas que lemos no relatório do INSERM de 2004, sobretudo em relação à escolha dos parâmetros da avaliação. Ao se utilizar do princípio da medicina baseada em provas, manifestava-se a barreira do efeito placebo de um medicamento, já que tal efeito é irreplicável em tratamentos psicoterápicos ou psicanalíticos nos quais a influência do terapeuta (por sugestão ou transferência) está necessariamente presente:

Primeiro, era preciso testar a diferença entre a inexistência e a existência de tratamento, a fim de poder comparar o efeito da passagem do tempo (ou da evolução espontânea) com a 
eficácia de um tratamento. Em seguida, era necessário fazer intervir o princípio da aliança terapêutica (sugestão, transferência etc.) [...]. Por último, era indispensável levar em conta a subjetividade das pessoas interrogadas. Daí a ideia de pôr em dúvida a autenticidade de seus depoimentos e desconfiar da influência do terapeuta (Roudinesco, 2000, p. 33).

Em suma, repetiu-se o insucesso das inúmeras pesquisas, já que não conseguiram comprovar estatisticamente a eficácia dos tratamentos, pois "os pacientes nunca se diziam curados de seus sintomas, porém transformados ( $80 \%$ dos casos) por sua experiência do tratamento" (Roudinesco, 2000, p. 33). Em outras palavras, as psicoterapias e a psicanálise apareciam como eficazes ao mesmo tempo em que não eram objetiváveis, não sendo possível transcrever o sucesso em estatística. A transformação subjetiva, relatada como um bem-estar ou como uma melhora nas relações sociais, profissionais ou sexuais em detrimento da cura, entendida como a remissão dos sintomas previamente detectados, reafirmava a exterioridade da psicanálise e dos tratamentos do psiquismo de modo geral em relação ao discurso médico.

Essa constatação não foi exclusiva das pesquisas de avaliação da eficácia da psicanálise. Em 1933, Freud (2010b, p. 315) já presenciara a seu tempo as tentativas de quantificação dos resultados de uma análise, respondendo às críticas quanto à impossibilidade de fornecer uma estatística de seus resultados: "A psicanálise é realmente uma terapia como outras. Tem seus triunfos e suas derrotas, suas dificuldades, restrições, indicações". O Instituto Psicanalítico de Berlim havia publicado um relatório sobre sua primeira década de trabalhos e Freud argumentou sobre os sucessos terapêuticos relatados, sem motivos para "gabar-se, nem para envergonhar-se", afirmando que as estatísticas não são instrutivas, sendo mais útil a indagação de experiências individuais.

Após 1970, com o aumento da expectativa de vida no Ocidente, multiplicaram-se os mal-estares e, com isso, cresceu a preocupação dos responsáveis pelas políticas de saúde pública com os custos dos tratamentos com qualquer patologia, centrados na busca pelo melhor custo-benefício, tanto no campo da medicina e da psiquiatria como no da psicologia e da psicoterapia (Roudinesco, 2005).

A vinculação da boa medicina àquela de menor custo fez proliferarem os estudos e as avaliações de tratamentos. Certamente, seus efeitos benéficos incluíam a racionalização das despesas em saúde e 0 reembolso de medicamentos, mas a outra face se apresenta na excessiva racionalidade da avaliação predominante sobre a deliberação crítica. Esse apagamento da criticidade se torna visível quando, por exemplo, são hoje agrupados pacientes completamente 
distintos em seu sofrimento em perfis patológicos "semelhantes" (Roudinesco, 2005).

Em síntese, o que continua escapando à lógica da ciência é inominável, fora-de-sentido, aquilo que responde a uma causalidade singular. E a ciência que erradica a singularidade incorre no risco de produzir indivíduos equivalentes entre si, agrupados não só em uma amostra, mas em uma massa - o que não difere muito do observável nos totalitarismos, como mostrava Hannah Arendt (Lapeyre \& Sauret, 2005). A avaliação é sempre a avaliação de um conjunto, e nunca do um-a-um. Nisso ela é incompatível com a psicanálise, posto que a psicanálise se ocupa da singularidade, do um-a-um. Na psicanálise, não há comparação entre singulares, enquanto que a avaliação procede necessariamente pela comparação (Miller \& Milner, 2006).

Na França, especificamente, a prática da avaliação é obrigatória no campo médico desde 1991, regulada pela Association Nationale d'Accréditation et d'Évaluation en Santé (ANAES), criada em 1997 "com a firme intenção de incluir nesse sistema a perícia técnica das psicoterapias" (Roudinesco, 2005, p. 91). No domínio universitário, a avaliação se introduziu definitivamente na França com a criação da Agence d'évaluation de la recherche et de l'enseignement supérieur (AERES), em 2006, a fim de rentabilizar as pesquisas realizadas na universidade. Fruto da iniciativa de Jean-Marc Monteil, psicólogo social cognitivista, a agência condensou iniciativas anteriores, tornando-se a única no território nacional, composta por ministros escolhidos e nomeados por decreto (Miller, 2008).

\section{O engodo da eficácia: a medicina fundada em provas}

O relatório do INSERM, inserido nessa "ideologia da perícia" (Roudinesco, 2005) propõe-se a hierarquizar a eficácia das psicoterapias utilizando-se de técnicas da medicina. Para isso, ao propor avaliar a eficácia de uma terapia tal como se detecta a presença ou ausência da substância ativa de um medicamento, recorrem ao procedimento das meta-análises e à medicina fundada em provas.

A medicina fundada em provas (evidence based medicine) foi um conceito desenvolvido no Canadá nos anos 1980. Refere-se a um processo de pesquisa, avaliação e utilização de resultados da pesquisa para a tomada de decisões clínicas, ao constatar a existência de uma lacuna entre pesquisa e clínica e a dificuldade de processar a quantidade de informações produzidas e publicadas sobre determinado assunto (Despland, 2006).

Não obstante, o procedimento possui suas falhas e vieses metodológicos. Entre elas, a existência de uma zona sombria - na qual se situaria a psicanálise, no caso do relatório do INSERM -, que 
agrupa os tratamentos sem pesquisas e estudos suficientemente validados, resultando em fraca potência estatística para a abordagem avaliada. Possui ainda o risco de generalização de situações clínicas quando, por exemplo, deseja-se medir a ansiedade e congregam-se diferentes grupos em uma única categoria: a ansiedade entre estudantes em uma ocasião específica se transmuta na categoria genérica de "transtornos de ansiedade" (Fischman, 2005).

Despland (2006) cita o engodo da crença no menor custo dos tratamentos validados pela medicina fundada em provas, já que o intuito das avaliações é garantir ao Estado o melhor custo-benefício. Ao contrário, no campo da saúde o que ocorre é frequentemente o inverso, sendo os tratamentos mais caros aqueles validados, além dos vieses na publicação dos resultados. Por último, pode-se considerar o chamado efeito de fidelidade, que reflete o interesse do estudo ou da equipe de pesquisa em validar um dos métodos postos à prova, reduzindo a suposta "neutralidade" do estudo.

Seguindo os princípios da medicina fundada em provas, no caso da avaliação das psicoterapias, três principais documentos encarregaram-se das pesquisas recentes nesse domínio: um relatório inglês do respectivo Ministério da Saúde (Department Of Health, 2001), um americano, produzido pela American Psychological Association (Sartorius, N., De Girolamo, G., Andrews, G., German, A. \& Einsenberg, L., 1993), e o relatório francês do INSERM (Despland, 2006). Nessa conjuntura, ganham espaço as psicoterapias que mais se aproximam de um modelo científico, como as cognitivocomportamentais.

\section{Considerações finais}

As conclusões do documento provocaram revolta nos psicanalistas, que se articularam com o então ministro da saúde, Philippe DousteBlazy, para a retirada do documento de circulação e do site do Ministério da Saúde. O ministro assumiu a discussão dos psicanalistas e reconheceu que o relatório trazia conclusões enviesadas.

As falhas do relatório, bem como seu excesso de cientificidade, foram os pontos considerados: interesses estavam em jogo ao promover as TCCs, mais rápidas e menos custosas para o Estado, em detrimento de outras abordagens. Diversos fóruns de debate e articulação foram engendrados, conjugando psicanalistas de diferentes associações e correntes teóricas, a fim de fazer frente à muralha antipsicanálise construída nesse período na França. As consequências mais duras das conclusões incisivas do relatório do INSERM em desfavor da psicanálise seriam sentidas quase uma década depois, em 2012, com a publicação de documentos oficiais interditando o tratamento psicanalítico do autismo. 
No ano de 2012, um relatório da Haute Autorité de Santé (HAS) condenou as abordagens psicanalíticas no tratamento do autismo por falta de dados sobre sua eficácia, baseada na metodologia da medicina fundada em provas. A HAS, entidade independente composta por especialistas (médicos, acadêmicos), havia sido criada em 2004 para "avaliar cientificamente, promover boas práticas e bom uso dos cuidados em saúde" (Perrone, 2012, p. 99), sendo estes os que promovem o melhor custo-benefício para o Estado.

A iniciativa da HAS deu origem ao projeto de lei do deputado Daniel Fasquelle, que visava "proibir as práticas psicanalíticas no acompanhamento de pessoas autistas, a generalização dos métodos educativos e comportamentais e a realocação de todos os financiamentos existentes para esses métodos" (França, 2012). Os argumentos de Fasquelle para a defesa do projeto reeditam aqueles do relatório do INSERM, que parecia esquecido, como o argumento de que a França estaria "atrasada" em relação aos outros países pela forte influência exercida pela psicanálise (Perrone, 2012).

Entretanto, o curso das propostas da HAS para o autismo tende a se modificar. Após a força da oposição dos psicanalistas ao relatório de 2004 do INSERM, novos estudos sobre a eficácia das psicoterapias foram conduzidos. Em conjunto com os centros hospitalares de Paris Necker, Pitié-Salpetrière e Tours, o INSERM conduziu um estudo sobre as abordagens psicoterapêuticas do autismo em 2014, na tentativa de preencher as lacunas deixadas pelo documento de 2004 (Guillot, 2014). Novos métodos foram utilizados, para além da Evidence based medicine, procurando responder a questões de ordem qualitativa, tal como: "Por que, como e em que condições, uma psicoterapia age?" (Guillot, 2014). Além disso, levou-se em consideração a relação terapêutica estabelecida, o ambiente no qual a criança vive, entre outros fatores.

Apesar de a recondução dos estudos sobre a eficácia ter ampliado o escopo das análises, ao constatar a falha na quantificação das mudanças do funcionamento subjetivo, e a fim de redirecionar o rumo das políticas de saúde, permanece a necessidade de cifrar, medir e comprovar: o número e o dígito garantem a existência real. Então, inseridos (ainda que resistentes) na lógica do mercado de produção de necessidades, é possível que se motive ainda a necessidade de criação de uma metodologia apropriada para a avaliação de psicoterapias de longa duração, da psicanálise e de outros métodos não favorecidos pela medicina fundada em provas (Fischman, 2005).

Afinal, como parte desse contexto neoliberal que atribui especial importância à cifra, resta à psicanálise "prestar contas" de sua prática, mesmo que não haja cifras suficientes para solucionar essa equação. Um começo possível é demarcar, na consistência interna de 
sua teoria, o que entende por eficácia, tendo em vista os efeitos terapêuticos que é capaz de produzir.

\section{Referências}

Aflalo, A. (2012). O assassinato frustrado da psicanálise. Rio de Janeiro: Contra Capa.

Department Of Health. (2001, fevereiro). Treatment choice in psychological therapies and counselling. Evidence based practice guideline. London. Recuperado em 16 de outubro de 2014

de: http://webarchive.nationalarchives.gov.uk/20130107105354/ht tp://www.dh.gov.uk/prod_consum_dh/groups/dh_digitalassets/ @dh/@en/documents/digitalasset/dh_4058245.pdf

Despland, J. N. (2006). L'évaluation des psychothérapies. L'encéphale, 32 (2), 1037-1046. doi: 10.1016/S00137006(06)76282-0

Dunker, C. I. L. (2011). Estrutura e constituição da clínica psicanalítica: uma arqueologia das práticas de cura, psicoterapia e tratamento. São Paulo: Annablume.

Expertise Collective. (2004). Institut national de la santé et de la recherche médicale (INSERM). Psychothérapie. Trois approches évaluées. Paris, 553p.

Fischman, G. (2005). Évaluation des psychothérapies selon les principes de I'Evidence-based Medicine. Enjeux et scientificité du rapport de I'Inserm. Annales Médico Psychologiques, 163, 769-779. doi: 10.1016/j.amp.2005.08.002

Foucault, M. (1988). História da sexualidade I: a vontade de saber. Rio de Janeiro: Edições Graal.

França. (2012). Proposition de Loi du 24 janvier 2012. Assemblée nationale. Visant l'arrêt des pratiques psychanalytiques dans l'accompagnement des personnes autistes, la généralisation des méthodes éducatives et comportementales et la réaffectation de tous les financements existants à ces méthodes. Recuperado em 14 de novembro de 2014 de: http://www.assembleenationale.fr/13/propositions/pion4211.asp

Freud, S. (2010a). O mal-estar na civilização. In: S. Freud (Ed.). Obras completas (1930-1936), (trad. Paulo César Souza) (v. 18, pp. 13-124). São Paulo: Companhia das Letras. (Obra original publicada em 1930).

Freud, S. (2010b). Esclarecimentos, Explicações, orientações. In: S. Freud (Ed.) Obras completas (1930-1936), (trad. Paulo César Souza) (v. 18, pp. 294-321). São Paulo: Companhia das Letras. (Obra original publicada em 1933). 
Grosbois, P. (2007). Usage légal du titre de "psychothérapeute": Stratégies des acteurs concernés [Legal use of psychotherapist title: Strategies of concerned actors]. Pratiques Psychologiques, 13(4), 381-400.

Guillot, V. (2014). Autismo: o Inserm valida a psicoterapia psicodinâmica. Lacan Quotidien, 447, 13 dez. 2014. Recuperado em 23 de janeiro de 2015 de: http://www.lacanquotidien.fr/blog/wpcontent/uploads/2014/12/LQ-447.pdf

Lapeyre, M. \& Sauret, M-J. (2005). La psychanalyse avec la Science. Cliniques Méditerranéennes, 71(1), 143-168. doi: $10.3917 / \mathrm{cm} .071 .0143$.

Martins, C. R. (2012). Psicanálise e Psicoterapia: de que se trata? Tese de Doutorado. Universidade Federal do Rio de Janeiro, Rio de Janeiro, RJ.

Miller, J-A \& Milner, J-C. (2006). Você quer mesmo ser avaliado? Entrevistas sobre uma máquina de impostura. Barueri, SP: Manole.

Miller, G. (2008). Dialogue avec des méconnus. Département de Psychanalyse Paris VIII. Recuperado em 23 de abril de 2014 de:

http://www.departementpsychanalyse.com/documents.aspx?Pa $\mathrm{ge}=8$

Perrone, C. (2012, agosto). A polêmica do autismo na França. SIG Revista de psicanálise, Porto Alegre - RS, 1(1), 99-102. Recuperado em 16 de outubro de 2014 de: http://www.sig.org.br/_files/uploads/image/revSIG_Num1_Exp ediente.pdf

Roudinesco, E. \& Plon, M. (1998). Dicionário de Psicanálise. Rio de Janeiro: Zahar.

Roudinesco, E. (2000). Por que a psicanálise? Rio de Janeiro: Zahar.

Roudinesco, E. (2005). O paciente, o terapeuta e o Estado. Rio de Janeiro: Jorge Zahar.

Sartorius, N., De Girolamo, G., Andrews, G., German, A. \& Einsenberg, L. (1993). Treatment of mental disorders. A review of effectiveness. Washington, WHO: American Psychiatric Press.

\section{Endereço para correspondência}

\section{Letícia Vier Machado}

Universidade de São Paulo

Instituto de Psicologia

Avenida Professor Mello Moraes, 1721, Butantã, CEP 05508-030, São Paulo - SP, Brasil

Endereço eletrônico: leticiaviermachado@gmail.com

Fernando Aguiar

Universidade Federal de Santa Catarina 
Campus Reitor João David Ferreira Lima, s/n, Trindade, CEP 88040-900, Florianópolis - SC, Brasil

Endereço eletrônico: fernando.aguiar@ufsc.br

Recebido em: 23/09/2015

Reformulado em: $18 / 11 / 2016$

Aceito para: 18/11/2016

\section{Notas}

* Doutoranda em Psicologia Escolar e do Desenvolvimento Humano no Instituto de Psicologia da Universidade de São Paulo (IPUSP). Graduada em Psicologia pela Universidade Estadual de Maringá (UEM). Mestre em Psicologia pelo Programa de Pós-Graduação em Psicologia da Universidade Federal de Santa Catarina (UFSC), Florianópolis - SC, Brasil.

** Doutorado em Filosofia e Pós-doutorados em Filosofia e Psicologia na Universidade Católica de Louvain (UCL). Professor do Departamento e do Programa em Pós-Graduação em Psicologia na Universidade Federal de Santa Catarina (UFSC), Florianópolis - SC, Brasil. 